\title{
The Synthesis of Silver Nanoparticles and Study the Antibacterial Effect of Saffron (Crocus sativus L) on Pathogenic Bacteria
}

\section{Thamer Mutlag Jasim*}

Department of Laboratory Clinical Science, Mustansiriyah University, Iraq

*Corresponding Author: Thamer Mutlag Jasim, Department of Laboratory Clinical Science, Mustansiriyah University, Iraq.
Received: June 08, 2020

Published: March 25, 2021

(C) All rights are reserved by Thamer Mutlag Jasim.

\begin{abstract}
Introduction: Crocus sativus is a member of Iridaceae family and its use in health management in practice. Antibacterial activity of synthesized silver nanoparticle was achieved by agar well diffusion method against Streptococcus pneumonia, Haemophilus influenzae, Klebsiella pneumonia, Staphylococcus aureus. The green synthesized silver nanoparticle can be used in the field of medicine, due to their high antibacterial activity. Plants are the richest source of natural antibacterial agents. The present study was carried out to evaluate the antibacterial effect of (Crocus sativus) Saffron.

Methods: Saffron was extracted with water and methanol. Hence methanol is a better solvent than water.

Result: The biosynthesized AgNPs showed significant effect against S. pneumonia, H. influenzae, K. pneumonia S. aureus, so it can be used in biomedical application.

Conclusion: Silver nanoparticles from saffron possess very good antibacterial activity which makes them potent sources of antibacterial agent.
\end{abstract}

Keywords: Nanoparticle; Green Herb; Pathogenic Bacteria; Antibacterial; Saffron (Crocus sativus) L

\section{Introduction}

Nanotechnology has become a rapidly growing field of research because of the unique properties and broad range of application of nano bioactive materials in different areas of industrial and biochemical science [1,2]. Saffron is one of the most expensive spices in the *word that has been considered as alternative treatment options which is cultivated in Iran, India [3]. Different part of saffron including stigma, leaves, stamen and colora represent antimicrobial activity. It contains a variety of chemical constituents such as crocin, crocin and other flavonoids, utilized for therapeutic processes [4-6]. The herbal of chemical which are including ter- penoves, flavones, ketones, aldehyde, amides and carboxylic acids, they are directly involved to the reduction of ion and the formation silver nano particles [7]. The toxicity of very nanoparticle depends on the size and rate of ion emission. Also antibacterial effects of silver nanoparticles are attributed to the three-dimensional structure of the cell of gram positive and gram negative bacteria [8]. The importance of silver ion has been also found in the treatment of burn wound by various researchers who studied the antimicrobial properties of silver nanoparticles against virulent pathogens [9]. There are three main sources for the synthesis of silver nanoparticles by biological methods such as bacteria, fungi, and plant extracts $[10,11]$. The anticancer activity of saffron compound related 
to antioxidant properties of carotenoid of saffron. Further in depth studies need to define efficacy of saffron cancer and treatment and prevention the scarcity and expense in obtaining large quantity of saffron may provide independent to human chemo preventive and cancer treatment using this agent. Saffron can protect the lung from pathological changes and can decrease progress of asthma in sensitized guinea pig. Saffron in combination of honey reduced the coarse of treatment in children with pneumonia. The currency of pneumonia was much less in saffron group of six weeks [12]. Extract of Crocus sativus against various have confirmed an improvised activity against bacteria and fungi used as test organisms [13]. The aim of the present study to investigate the antibacterial effect of aqueous and methanolic extract of $C$. sativus nanoparticle on the pathogenic bacteria isolated from the patient with pneumonia.

\section{Materials and Methods}

\section{Sample collection}

Sample were collected from the local market and identified by A bokreb botany center.

Preparation of the aqueous and methanol crude extract

The collected flowers were washed with distilled water. The materials were powdered separately by using electric grinder. 50 grams of dried powder was filled in the thimble and extracted with $150 \mathrm{ml}$ of water and methanol successively up to $48 \mathrm{~h}$ accompanying shaking and stirring $[13,14]$. The mixture were then undergone a coarse filtration through Whatman filter paper separately. The filtrate obtained were evaporation by rotary evaporator at 5 to 6 rpm and $65 \mathrm{c}$.

Test organisms for evaluation of antibacterial activity

Authentic pure cultures of bacteria isolated from the patient with pneumonia in Al Yarmuk hospital like S. pneumonia, klebsiella pneumonia, Staphylococcus aureus, H. influenza.

\section{Synthesis of silver nanoparticle}

$10 \mathrm{ml}$ of extract was treated with $90 \mathrm{ml}$ of $1 \mathrm{mv}$ silver nitrate solution and kept in room temperature. Subsequently the synthesis of silver nano particle was initially identified by brown colour formation and further monitored by measuring UV-vis spectra of the reaction mixture.
Determination of MIC (Minimal Inhibitory Concentration) and MBC (Minimal Bactericidal Concentration)

The MIC value of Ag-Nps and extract were determined by broth microdilution assay. The Ag-Nps serially diluted two fold with deionized water concentration ranging for $50-7.8 \mathrm{mg} / \mathrm{ml}$. were extract were serially diluted to fold with 10\% (DMS) containing 1-1.56 mg $\mathrm{ml}$ after shaking $100 \mathrm{ml}$ of dilute AgNps. 0.1 extract was added to each well of 96 well microliter plates. Microbial suspension were adjusted to 00.5 MacFarland and at 35-42 diluted to $1 \times 10$ oss 6 $\mathrm{CFU} / \mathrm{ml}$ then $100 \mathrm{ml}$ of the suspension was added to each well and incubated at $35-42$ c for 24 hour MIC value were determined at the lowest concentration compound that incubated bacteria after 24 hours [14] water concentration were serially diluted two fold with deonised Ag-NPs.

\section{Results}

Table 1 have shown zone of inhibition $\mathrm{mm}$ of clinical isolation and concentration of aqueous Saffrone. Table 2 have shown zone of inhibition in mm of clinical isolation and concentration of methanolic extract of Saffron. Table 3 have shown zone of inhibition mm of clinical isolation of Saffron ad concentration of Saffron and nanoparticle. Table 4 have shown antibacterial activity of silver nanoparticle of Saffron of Ag.

\begin{tabular}{|l|c|c|c|c|}
\hline $\begin{array}{c}\text { Bacterial } \\
\text { species }\end{array}$ & Concentration & In mm & & $\begin{array}{c}\text { Antibiotic } \\
\text { positive } \\
\text { control }\end{array}$ \\
\hline St. pneumonia & $1 \%$ & $3 \%$ & $5 \%$ & \\
\hline S. aureus & 10 & 13 & 14.5 & 10 \\
\hline H. influenza & 9 & 10 & 11.3 & 7 \\
\hline $\begin{array}{l}\text { Klebsiella } \\
\text { pneumonia }\end{array}$ & 9 & 10 & 11.3 & 7 \\
\hline
\end{tabular}

Table 1: Zone of inhibition in mm of clinical isolation and concentration of saffron with water.

\begin{tabular}{|l|c|c|c|}
\hline Bacterial spp & Concentration & In mm & \\
\hline & $1 \%$ & $3 \%$ & $5 \%$ \\
\hline St. pneumonia & 14 & 14 & 15 \\
\hline S. aureus & 13 & 13 & 14 \\
\hline H. influenzae & 12 & 12 & 13 \\
\hline K. pneumonia & 11 & 11 & 12 \\
\hline
\end{tabular}

Table 2: Zone of inhibition in mm of clinical isolation and concentration of saffron with methanol. 


\begin{tabular}{|l|c|c|c|c|}
\hline \multicolumn{1}{|c|}{ Bacterial spp } & & & & \\
\hline St. pneumonia & 58 & 116 & 4.20 & 6.10 \\
\hline S. aureus & 56 & 112 & 2.40 & 2.5 \\
\hline H. influenza & 10.3 & 20.6 & 2.5 & 2.5 \\
\hline $\begin{array}{l}\text { Klebsiella } \\
\text { pneumonia }\end{array}$ & 100 & 200 & 3.2 & 3.2 \\
\hline
\end{tabular}

Table 3: Bacterial activity of silver nano particle and aqueous saffron extract AgNps.

\begin{tabular}{|l|c|c|c|c|}
\hline Bacterial spp. & & & & $\begin{array}{c}\text { Antibiotic positive } \\
\text { control }\end{array}$ \\
\hline St. pneumonia & 61 & 122 & 8 & 7 \\
\hline S. aureus & 59 & 118 & 6 & 8 \\
\hline H. influenza & 11 & 22 & 4 & 8 \\
\hline K. pneumonia & 120 & 240 & 5 & 5 \\
\hline
\end{tabular}

Table 4: Bacterial activity of silver nano particle and saffron extract with methanol.

\section{Discussion and Conclusion}

Saffron extract quickly reduces Ag to Ago and enhance synthesis of silver nanoparticle with highly antibacterial activity [15]. Addition of the aqueous and methanolic herbal extract to $1 \mathrm{~mm}$ aqueous $\mathrm{AgNO}_{3}$ solution resulted in change of colour with 5 - 10 minutes which can be varied according to the plant species chosen. The reason could be the qualitative variation in the formation of SNps or availability of $\mathrm{H}$ or to reduce the silver. The change in colour was obtained which resulted due to the excitation of the surface plasmin Resonance (SPR) variation of the silver nanoparticle formed. The green herb are the site of photosynthesis and accessibility of more the ion to reduce the silver nitrate into silver nanoparticle. Green synthesis of silver nanoparticle by saffron and their bioefficacy against pneumonia. The study investigated the influence of different concentration of $C$. sativus $\mathrm{L}$ against bacteria isolated from the patient with pneumonia. This result agree with Ghodsiel Bagherzade., et al. 2017 [16] who report the biosynthesized AgNps showed significant antibacterial effect against pathogenic bacteria. And agree with Ghodsieh Bagherzade., et al. who report that the biosynthesized AgNps had an inhibiting activity against K. pneumo- nia [17]. And agree with Jeff., et al. 2012 [18] who report NP therapies promise for treating a wide variety of bacteria that are not easily killed by routine antimicrobial agents [19]. And agree with Fahidi., et al. 2002 [20] who report the effect Crocus sativus against bacteria. Silver nanoparticle destroy bacteria by membrane demolition [20]. A green method has been reported for the synthesis of AgNPs using $C$. sativus extract as reducing and capping agent. The silver nanoparticle show high antibacterial activity when assayed by agar well diffusion method. This green synthesized nanoparticle could be used in the medical field against human disease due to their high efficiency as antibacterial agent [21-24]. The present study agreement with Thamer., et al. 2018 [25] who report the green synthesis of silver nanoparticle (AgpNs) by using the flower extract have high antibacterial activity and agreement with Dipnaker C, Murugan proposed that the biosynthesized Ag-NPs using Iresine herbstii leaf aqueous extract represented excellent antimicrobial activity [26,27]. Furthermore, it is suggested to evaluate the effect of active components of the extracts and antimicrobial preservatives used in food, health, pharmaceutical and cosmetic industries and to elucidate the exact mechanisms of action by which extract exert their antimicrobial effect to identify the active ingredients which can be used in drug development program for safe health care services. Hence, our results are promising and prove to be an important step in the treatment of pneumonia.

\section{Bibliography}

1. Ulbricht C., et al. "An evidence systematic review of saffron (Crocus sativus) by the natural standard Rashid, Mohammad research collaboration". Journal of Dietary Supplements 8 (2011): 58-114.

2. Carmolinas MR., et al. "The chemical composition of saffron: colour, taste and aroma" (2006).

3. Md Mamun., et al. "Comparative study on the antibacterial activity of four medicinal plant leaves of different ages". International Journal of Pharmaceutical Science Invention 3.31 (2014).

4. JB Harborn. Phytochemical methods, Champan and Hall publication. London (1992): 7-8.

5. Carmona M., et al. "Anew approach to saffron aroma". Critical Reviews in Food Science and Nutrition 47 (2007): 145-159. 
6. Syed Muzaffar., et al. "In vitro bactericidal and fungicidal activities of various extract of Saffron (crocus sativus L) stigmas from jammu and Kashmir, India". Cogent Food and Agriculture 2.1 (2016).

7. M Vanaja., et al. "Herbal plant synthesis of antibacterial nanoparticle by Solanum trilobatum and its characterization". International Journal of Metals (2014): 8.

8. Anahita., et al. "Evaluation of Reciprocal pharmaceutical effects and Antibacterial Activity of Silver Nanoparticle and Methanolic Extract of Crocus Sativus L. (saffron) on Some Bacterial Strains". International Journal of Enteric Pathogens 5.1 (2017): 18-23.

9. Sahani M. "Patening in Saffron". Journal of Intellectual Property Rights 444 (2012): 530-535.

10. Khushboo Singh., et al. "Antibacterial activity of synthesized silver nanoparticle from Tinospora cordifolia against multi drugs resistant strain of Pseudomonas aeruginosa isolated from burn patients". Nanomedicine and Nanotechnology (2014).

11. Gonpy Vian MA., et al. "Identification and quantification flavanoids anthicyanins and leutin diesters in tepals of Crocus sativus by ultra performance liquid chromategen coupled to dode aray and ion trop mass spectrometry detections". 44 (2013): 496-451.

12. Bhargava V. "Medicinal used and pharmaceutical propertied of crocus sativys L9saffron". International Journal of Pharmacy and Pharmaceutical Sciences 3 (2011): 33-35.

13. Arshad Husain Rahmani., et al. "Saffron and its active ingredients; role in the prevention and treatment of disease". Pharmacognosy Journal 9.6 (2017).

14. Imm AR., et al. "Enhanced antibacterial activities of leonuri herba extracts containing silver nanoparticles". Phyto therapy Research 26.8 (2012): 1249-1255.

15. Daneshmandi S., et al. "Evaluation of the drug synergistic and antibacterial effects of cuminum cyminum essential oil (Persian)". Arak Medical University Journal 13.2 (2010): 75-82.
16. Mann A., et al. "Therapeutic role of saffron and honey in pneumonia in children". Current Pediatric Research 10 (2006): 2527.

17. A Ahmad., et al. "Extracellular biosynthesis of silver nanoparticle, using the fungus fusarium oxysoium". Biochemistry and Molecular Biology 28 (2003): 313-318.

18. K Vijagaaghavan., et al. "Biometic synthesis of silver nanoparticle by aqueous extract of syzygium roiuaticum". Matterletter 75 (2012), pp. 33-35.

19. Shrin., et al. "Antibacterial activity of silver nanoparticle mg/ $\mathrm{ml}$ and their combination with Zataria multifora essential oil and methanol extract". Jundishapur Journal of Microbiology 9.10 (2016).

20. Ghodsieh Baghherzade., et al. "Green synthesis of silver nanoparticle using aqeous extract of ssafron wastagesand its antibacterial against six bacteria". Asian Bacific Journal of Tropical Biomedicin (2016): 1-7.

21. Vahidi H., et al. "Antimicrobial properties of crocus sativus L". Iranian Journal of Pharmaceutical Research (2002): 33-35.

22. Jeff., et al. "In vitro antimicrobial studies of silver carbine complexes : activity of free and nanoparticle carbine formulation against clinical isolates of pathogenic bacteria". Antimicrobe Chemotherapy 67 (2012): 138-148.

23. AKK Jha K., et al. "Plant system: nature nanofactory". Colloids and Surfaces B: Biointerfaces 73 (2009): 219-223.

24. V Dyantha., et al. "The Burgening therapeutic molecule and its green synthesis" (2017).

25. Thamer M Jasim., et al. "Synthesis of herb silver nanoparticle and study the effect against some bacterial infection". Journal of Pharmaceutical Sciences and Research 10.7 (2018): 16491651.

26. Dipanker $\mathrm{C}$ and Murugan S. "The green characterization and evaluation of the biological activities of silver nanoparticles synthesized from iresine herb leaf aqueous extracts". Colloids and Surfaces B: Biointerfaces 98 (2012): 112-119. 
27. Thamer Mutlag Jasim. "The antibacterial Effect of Diode laser And silver nanoparticle Against Biofilm bacteria". Journal of Global Pharma Technology JGPTV (2018).

\section{Assets from publication with us}

- Prompt Acknowledgement after receiving the article

- Thorough Double blinded peer review

- Rapid Publication

- Issue of Publication Certificate

- High visibility of your Published work

Website: www.actascientific.com/

Submit Article: www.actascientific.com/submission.php

Email us: editor@actascientific.com

Contact us: +919182824667 